DOI: http://dx.doi.org/10.24818/jamis.2019.03002

\title{
Acculturation and accounting standardization strategies
}

\author{
Rahma Ben Salem ${ }^{a, 1}$, Salma Damak Ayadi ${ }^{b 1}$ and Rahim Kallal \\ aISIG, University of Kairouan, LIGUE, University of Manouba, Tunisia \\ ${ }^{\mathrm{b}}$ IHEC Carthage, University of Carthage, LIGUE, University of Manouba, \\ Tunisia \\ ${ }^{\mathrm{c}}$ IHEC Carthage, LEFA, University of Carthage, Tunisia
}

\begin{abstract}
Research question: The objective of this research is to develop a reliable and valid measurement scale for releasing new cultural attributes based on social psychology concepts and apply them afterwards in the accounting field. Motivation: Migration to International Accounting Standards Board (IASB) standards by a large and growing number of countries has marked the accounting field. However, this application varies from one country to another due to several environmental factors especially cultural ones. Idea: This paper puts the important issue of cultural differences in applying international financial reporting standards (IFRS) to the forefront and especially the strategies countries may apply when coping with the implementation of these standards within their local environment. Data: We selected a total of 33 items from these scales that match most with the objective of our survey. We also added the two questions posed by Berry to determine its acculturation strategies. We used 874 answers from different countries to our questionnaire. Tools: By taking Berry's typology, we conducted a cluster analysis to dynamic clouds using SPSS, which allows us to identify the different acculturation strategies used by respondents. Findings: Using Berry's acculturation model borrowed from social psychology and adopting an exploratory perspective based on the interpretive approach, we developed a measurement scale through which we identified five new

${ }^{1}$ Corresponding authors: Rahma Ben Salem, Assistant Professor, ISIG Kairouan, University of Kairouan, Tunisia Member of the LIGUE LR99ES24, ISCAE, University of Manouba, Email: rahmabs@hotmail.com; Salma Damak Ayadi, Full Professor, IHEC Carthage, University of Carthage, Tunisia, Member of the LIGUE LR99ES24, ISCAE, University of Manouba, Email: salmadamak@yahoo.fr.
\end{abstract}


acculturation attributes: interpersonal communication, work performance, openmindedness, ethnocentrism and knowledge of the host culture. We also found that the integration strategy is the most widespread strategy in a new cultural context. This finding corresponds to the convergence strategy that is most solicited by countries applying IFRS. Contribution: Our research is an adaptation and extension of the acculturation model across some countries that could function as a "map" of potential interventions to strengthen local application of IFRS.

Keywords: culture; acculturation attitudes; accounting standardization strategies; IFRS.

\section{JEL codes: $M 40$}

\section{Introduction}

Culture appears as "the internalized tank, carefully crafted and passed by the story of a set of values, rules and collective representations that operate in the depths of human relationships" (Sainsaulieu, 1997 p.163). To this end, the study of their evolutionary terms becomes an emergency for constraint societies to adapt quickly to external pressures.

However, from the definition of culture, we realize that this concept contains attributes that are less tangible to be measured easily. Thus, research in the field of acculturation involves a detailed understanding of stage situations of cultural change which assumes the even explanation of the structure of cognitive activity of individuals beyond mere assertions about the existence of standards, values and symbols.

The majority of studies (Berry, 1997; Masgoret and Ward, 2006) on acculturation focused on groups that have experienced cultural transitions especially immigrants. This sociocultural adaptation according to these authors requires an understanding of the relevant standards and rules that immigrants must learn to deal with cultural differences and determine their behavioral strategies (acculturation attitudes).

Since culture is a concept wrought to refer to societies in general and their fundamental regulations, it is difficult to identify cultural elements involved in the regulation of social relations. This poses a difficult epistemological problem and requires meticulous work in order to transpose the theoretical use in different cultures. The objective of this research is to transpose the study of acculturation to the accounting field. We seek to understand how people behave, interact and identify with those around them especially when they are in a new cultural context. 
In his cultural approach to accounting, Belkaoui (1990) demonstrated that accounting is a reflection of the cultural, linguistic and socioeconomic structures of a country. Therefore, the accounting harmonization is difficult because we cannot standardize practices without facing resistance in each country. Several studies have taken the ideas of Hofstede and Gray to forge the link between culture and the diversity of accounting systems. The major problem was how to approach culture as a determinant of existing accounting systems. As Gray (1988) argued: "In order to explore further the relationship between culture and accounting systems in an international context it is necessary to identify the mechanism by which values at the societal level are linked to values at the accounting subcultural level as it is these latter values which are likely to influence directly the development of accounting systems in practice."

Prior research provides various proxies for choosing the relevant cultural factors in accounting research. However, the key problem is that it fails to explore cultural factors rigorously. In fact, our proposal is to develop a reliable and valid measurement scale for releasing new cultural attributes, other than those used in previous studies, based on social psychology concepts and apply them afterwards in the accounting field.

In this perspective, the empirical approach is an important link in the research process as an interface between theory and reality that determines the reliability of results and the credibility of interpretations in order to visualize the nature and the extent of acculturation attitudes conducted in different countries.

The paper proceeds as follows. A brief review of the influence of culture on accounting systems and the epistemological positioning are presented in the first section. The second section is focused on the research methodology used to develop our measurement scale of acculturation attitudes. The statistical results are analyzed in the third section followed. In the last section, we discuss the findings.

\section{Culture influence on the development of accounting systems}

In reviewing previous research, we found that most of them have studied several factors to determine which ones have a significant impact on the choice of international standards by giving less importance to cultural factors. But the study of these has been advocated by Perera (1989) and Walton and Haller (2003) who have noted that culture is one of the most important factors affecting a country's accounting system. Thus, research in international accounting should take into account cultural differences.

The environmental factors frequently used in the accounting literature are: the economic system, the importance of the financial and capital markets, the financial 
backers, the political system, the legal system, the taxation system, the influence of the accounting profession etc. However, studying the impact of these factors only on the accounting systems seems insufficient because these factors are, in turn, influenced by very important factors that govern all these systems and are responsible for their development.

In fact, Belkaoui (1990) has shown that accounting is a reflection of the cultural, linguistic and socio-economic structures of a country. Therefore, harmonization is difficult because we cannot standardize practices without encountering resistance in each country (Stolowy, 1996). Although some studies have been concerned with culture, no previous study has succeeded in covering the different elements of culture and their effects on the choice of international standards. Thus, in developing a set of standards acceptable to all countries, the IASB faces a multitude of influences that represent different facets of economic, financial, political, cultural and social factors.

As a result, we aim to establish a diagnosis of the cultural and institutional factors relating to each country and to study their impact on the choice of international benchmark. Drawing on prior work on global culture from Hofstede (1980) and Gray (1988), cross cultural research (Doupnik \& Salter, 1995; Jaggi \& Low, 2000; Dahawy et al. 2002; Archambault \& Archambault, 2003; Judge et al., 2010; Shima \&Yang, 2012) established a close match between culture areas and patterns of accounting systems internationally. They argued that cultural values may affect accounting systems and play a role in the standard adoption process. According to Ding et al. (2005), cultural values are predictive of IFRS adoption and are more important than legal origin in explaining differences between national standards and IFRS.

The importance of culture in influencing the process of accounting policy formulation and the choice of standardization strategy across nations is well documented. The study of Violet (1983) and Samuel and Manassian (2011), which focused on the cultural factor and the international accounting harmonization, considered that the success of the IASB is limited by cultural variables and culture could be an impediment to development of accounting.

Perera (1989) shows how the accounting systems of the different countries are influenced by their cultural values that shape their accounting practices. Furthermore, D'Arcy (2001) noted that the approaches used to establish accounting standards are a function of cultural values and country specific factors. In their study, Zeghal and Mhedhbi (2006) assumed that developing countries with AngloAmerican culture are more likely to adopt IFRS. Besides, using training opportunities in the accounting profession and corruption as cultural factors, Nurunnabi (2015) found that the scarcity of training opportunities in the accounting profession and the high level of corruption in Bangladesh have a negative influence on implementing IFRS. It is found that a lack of professional ethics among auditors 
and company accountants is perceived to be inhibiting effective IFRS implementation. These findings justify the necessity of including cultural issues in explaining the IFRS adoption in a country.

In this area, the most used approach is the ethical approach (Bollinger \& Hofstede, 1987; Usunier 1992). In our work, we adopt a new approach to identify cultural attributes and to understand the socio-cultural adaptation process of individuals and to match it with the choice of an accounting standardization strategy.

We rely on the interpretive paradigm that aims to understand reality. It focuses on the role of accounting, accountants and standardization in the social regulation and on the function of accounting in social relations. It was considered by Dumontier and Teller (2001) having a more fluid vision of the world and of the social reality depending on the human being; his interpretations, beliefs and behaviors.

Our research will be conducted on the borders of exploratory theoretical approach that allows researcher to propose innovative theoretical results through two main objectives: the search for an explanation and the search for understanding. As we proposed a combination of the social aspect and the accounting one, we resorted to the social psychology discipline through Berry's acculturation model and the accounting discipline through the choice of accounting standardization strategy. According to Berry's conceptualization, acculturation can be determined with respect to two major issues: "cultural maintenance (to what extent are cultural identity and characteristics considered to be important, and their maintenance strived for); and contact and participation (to what extent should they become involved in other cultural groups, or remain primarily among themselves)" (Berry, 1997: 9).

These two issues define an intercultural contact space and their crossing leads to four types of strategies.

\section{Maintenance of culture and identity}

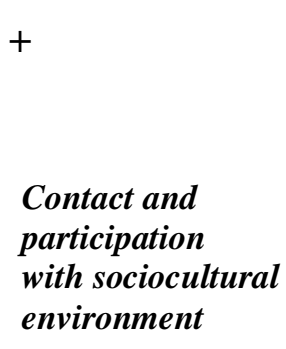

\section{-}

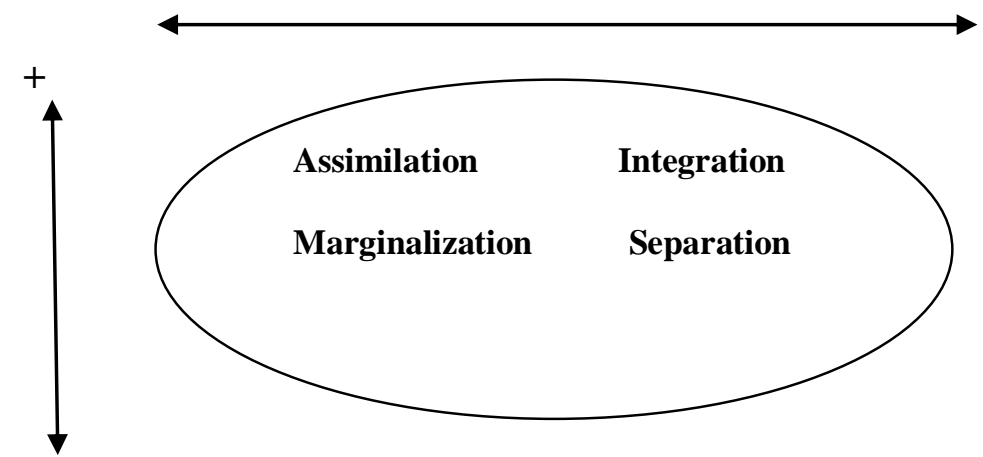

Figure 1. Acculturation strategies 
In fact, when people do not want to maintain their cultural heritage and seek interaction with other cultures, this defines a "strategy of assimilation." However, when individuals attach to their culture of origin and avoid interactions with others; a "strategy of separation" is defined. When there is both an interest in native culture and an interest in interaction with other groups, an "integration strategy" explains this situation. Finally, when there is less interest to maintain the original culture and less interest to participate in the culture of the dominant group, a "marginalization strategy" is defined. Note that this presentation was based on the assumption that cultural groups and their members have the freedom to choose how they want to engage in intercultural relations.

We suggest to transpose these four acculturation strategies in the context of accounting harmonization especially standardization strategies. In fact, we assumed that the host culture is the IASB and the culture of origin is the national culture of each country. We considered the IASB as a host culture for the following reasons:

- The aim of our research is to determine whether the national culture is an obstacle to migrate to IFRS. Thus, we can describe these standards as a cultural product presented by the IASB and would be accepted or rejected by the other cultural settings in different countries.

- According to the census made by the IASB website, there are more than one hundred countries using IFRS. So, this number makes IASB the major culture compared to other countries.

Use of IAS / IFRS

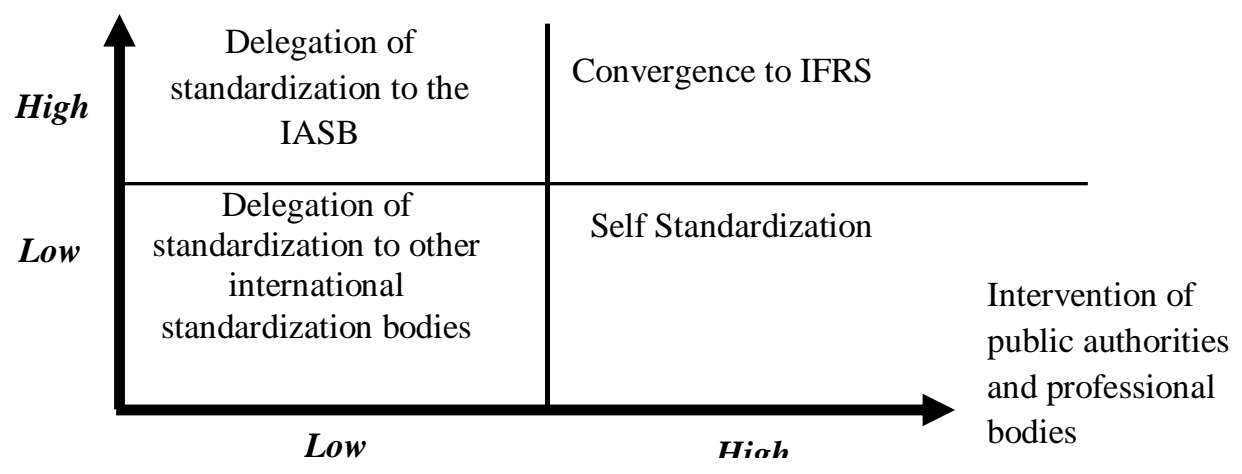

Figure 2. Standardization strategies

This typology is based on two criteria: the state and protessional bodies' intervention in the production of standards in any country and the use of IFRS in the shape of standards. Four standardization strategies are identified: 1) Delegation strategy to the IASB where neither the government nor the national professional organizations participate in the standards because firms in this case must refer directly to IFRS; 2 ) Self-standardization strategy where governments and/or professional bodies in each country produce standards without reference to IFRS which are their own; 3) 
Convergence strategy towards IFRS where governments and/or national professional organizations produce standards that converge to IFRS and 4) Delegation strategy to other international standardization bodies where governments and/or professional bodies in the country play no role, the task of standardization is assigned to other international standardization bodies.

From this classification, we attempt to establish the link between Berry's acculturation strategies and these standardization strategies.

1- The self-standardization strategy may be expected to correspond to the separation strategy which reflects the rejection of the dominant culture so, from an accounting perspective, the country wants to maintain its own accounting system that reflects their specificities.

2- The delegation strategy to other international standardization bodies' strategy would correspond to the marginalization strategy which the country entrusts the standardization mission to other international standards bodies with the aim of achieving regional harmonization to meet economic and political objectives.

3- The integration strategy would apply in the case of convergence to IFRS; it's about maintaining cultural identity and adopting the dominant culture.

4- The adoption strategy for IFRS would be consistent with the assimilation strategy which is explained by the abandonment of cultural identity to adopt the dominant culture.

In the next section, we present our empirical approach with two steps based on a questionnaire conducted in different countries.

\section{Empirical approach}

\subsection{Development of a measurement scale of acculturation attitudes}

As our study takes the form of an exploratory approach, we must look at the characteristics peculiar to our framework:

- The absence of similar or comparable previous research in accounting urges us to take more care in the selection of items.

- The development of the questionnaire and the interpretation of results must also take into account the risk of bias inherent to the specific problems of crosscultural validity of the instrument. Building on the findings of Hofstede (1987): "The comparison between cultures helps a lot to the understanding of each of them; by applying an identical questionnaire to comparable samples in a series of countries we can detect differences between the values in these countries." We will apply the same questionnaire to samples in different countries.

Development of exploratory survey

We seek to identify cultural factors involved in a process of acculturation to determine the attitudes of individuals when they are facing another cultural context. We invested more in previous research in the field of social psychology to structure 
our questionnaire. Some researchers (McGee, 1898; Berry, 1997) stressed that this acculturation process is similar to the socio-cultural adaptation process. Masgoret and Ward (2006) have defined the sociocultural adaptation as the ability to adjust or to negotiate interactions in a new cultural environment. It integrates knowledge, skills, communication, social interaction and adaptation to new ecologies, norms, values and worldviews.

Several studies (Berry, 1997; Ward \& Kennedy, 1999; Masgoret \& Ward, 2006) highlighted the importance of intercultural communication, linguistic competence, the frequency of cross-cultural contacts, interpersonal accessibility, social interaction ability and knowledge of the standards and values of the host culture in adopting a new cultural context. We referred to several surveys that carried out research in social psychology and treated the sociocultural adaptation. The literature review allowed us to identify our key cultural dimensions to discern our acculturation attitudes construct.

\section{Scale of socio-cultural adaptation}

To measure the socio-cultural adaptation, Searle and Ward (1990) constructed the Sociocultural Adaptation Scale (SCAS). According to Ward and Kennedy (1999), the SCAS is one of very few instruments of evaluation that has been specifically designed for use in cross-cultural research on the adaptation of individuals in a new cultural environment. It is focused on skills that are necessary for the daily management of social situations in new cultural contexts. According to Ward and Rana-Deuba (1999), this instrument is flexible and adapts easily to interviewed individuals' characteristics while keeping reliability.

\section{Scale of Cultural Intelligence}

According to Ang et al. (2006), working with people from different cultures may be difficult for individuals and their organizations because of cultural barriers that can hinder effective and efficient interactions (Gelfand et al., 2001; Lievens et al., 2003; Takeuchi et al., 2002). It is therefore important to understand why some people are more effective than others to deal with situations that are culturally diverse. This faculty is called in psychology the "Cultural Intelligence" and is defined as the ability of a person to adapt, operate and manage effectively in the new cultural contexts. It is relevant for world leaders, expatriates, professionals with international contacts, members of multicultural teams and anyone operating beyond national boundaries (Arora \& Rohmetra, 2010). Earley and Ang (2003) developed Cultural Intelligence Scale (CQS) which includes 20 items related to four dimensions namely: metacognitive dimension; cognitive dimension; motivational dimension and behavioral dimension. Ang et al. (2007) stated that the cross-validation analysis demonstrated the validity, stability and reliability of this scale in various samples, time and countries.

\section{Scale relationships with others}

Zinetti et al. (2004) constructed a scale assessing relationships with others named Relations with Other Scale (Echelle de Relations avec les Autres, ERA) which 
allows the individual to perform a self-analysis of their interactions with others. It contains 16 items and covers four major areas of relationships with others: openness to others, relational distance, personal and relational insight and pleasure in and through the relationship. According to the builders of this scale, ERA has good internal consistency, good external validity, excellent discriminant validity and good test-retest fidelity.

As we study the phenomenon of acculturation related to the migration from a national accounting system to international standards, we selected a total of twenty three items from these scales that match most with the objective of our survey. We also added the two questions posed by Berry to determine its acculturation strategies (Table 1).

Table 1. List of selected items

\begin{tabular}{l}
\hline Items \\
\hline 1. Building and maintaining relationships. \\
\hline 2. Managing my academic/work responsibilities. \\
\hline 3. Interacting at social events. \\
\hline 4. Working effectively with other work colleagues. \\
\hline 5. Interacting with members of the opposite sex. \\
\hline 6. Gaining feedback from other work colleagues to help improve my performance. \\
\hline 7. Expressing my ideas to other work colleagues in a culturally appropriate manner. \\
\hline 8. Changing my behaviour to suit social norms, rules, attitudes, beliefs, and customs. \\
\hline 9. I can see who are the others, their qualities and defects. \\
10. I can trust others. \\
\hline 11. I am aware of my qualities and my faults. \\
12. When interacting with individuals from another culture, I think it's important to keep \\
my identity and my characteristics. \\
\hline 13. I see that it is important to maintain relationships with individuals from another \\
culture. \\
\hline 14. I can benefit from other's experience. \\
\hline 15. I am able to easily tackle tough issues with others. \\
\hline 16. I manage to establish contact with people from other cultures. \\
\hline 17. I can separate from others. \\
\hline 18. I am aware of cultural differences between countries. \\
\hline 19. I adjust my cultural knowledge as I interact with people from a culture that is \\
unfamiliar to me. \\
\hline 20. I check the accuracy of my cultural knowledge as I interact with people from different \\
cultures. \\
\hline 21. I know the objectives of the IASB (International Accounting Standards Board). \\
22. I know the legal and economic systems appropriate to the application of IFRS. \\
23. I recognize that religious beliefs are involved when choosing the application of IFRS \\
\hline 24. I know the qualitative characteristics IFRS. \\
25. I know the content of IFRS. \\
\hline
\end{tabular}




\subsection{Acculturation dimensions}

In this part, we will define the dimensions of our theoretical construct "acculturation" that allow us to delineate the cultural characteristics responsible for the adaptation of an individual in a new cultural environment. From the literature review presented above, we found the multidimensionality of our construct. Thus, we have identified five dimensions that describe the phenomenon of acculturation namely:

- Interpersonal Communication (IC): Interpersonal communication includes interactions that allow individuals to exchange information, ideas and emotions. It can be verbal or nonverbal. Interpersonal communication is the basis of life in society since it lies in the relationship between individuals and within groups. Thus, according to Köhler (1951), the relationships between individuals are as important to the behavior of the whole as their composition because it is not just to share a set of beliefs and values, but also a communication model, emotional expression and skills. Although "culture comes as a content conveyed through communication," according to Berry (2004), the interpersonal communication becomes more difficult when there is a big difference between cultures. So we assume that the more exchange of information, the closer we are to each other, the more individual judgments are moderate and more likely to compromise.

- Academic/work performance (AWP): Labor needs to require interactions between different actors. Thus, each of his mental programs acquired in his social background, power relations, strategies and interdependencies in organized reports can escape the cultural influences because people cannot easily change their identity and culture through the doors of the workplace. However, observing relational abilities of a group of people at work allows us to define collective identities following the various interactions required by the job. According to Sainsaulieu (1997), the workplace which organizes the relations between individuals in intense cognitive and emotional links, is actually a source of cultural learning and is a center of socialization, self-definition and representation on the world. The professional community establishes working relations consisting of interpersonal, collective and hierarchical relationships that lead to discussions with colleagues, create differences by identifying oneself and affirm identities by imitation, which can sustain collective action. We assume that the more you interact with colleagues at work, the more you socialize with them, and the more you are able to appreciate and recognize yourself collectively.

- Open -mindedness $(\boldsymbol{O M})$ : This is an ability to understand diverse and new questions and to admit opposing views. It is a quality of mind of an individual who is tolerant, who communicates easily, and who is aware that his own vision is fallible. In other words, openness is the ability to handle a given situation in the most impartial way through free judgmental perspective, preconceived ideas and personal expectations. It allows to accept different views from ours and other people's choices by considering that disagreement does not mean the other is 
wrong. Thus, it improves the tolerance level by encouraging discussions with those who have different opinions from us helping others to understand our position and to avoid conflicts even if we are totally convinced of our perspective. We recognize that the more we are open-minded, the more we accept differing opinions of others, the more we call into question our analytical mind and perceived consensus.

- Ethnocentrism (EC): It is the tendency to focus on standards and values of our own society to analyze other companies and to see the world with its own culture and its own social group as a reference model. The ethnocentrism is a critical barrier to intercultural communication. The ethnocentric person relies on stereotypes to reject customs of other cultures. Ethnocentrism places the individual in a position of affirmation of the superiority of its cultural and the refusal to recognize others as equal. It is the image of his own group, which is defended by fear of being influenced by the culture of the other and of giving up old practices and traditions. Levi-Strauss (1952) considered ethnocentrism as "the tendency to repudiate all cultural manifestations and distant behavior of those with whom we identify" (Lévi-Strauss 1952, p.19). It appears as the major obstacle to the study of other societies. Therefore, we assume that the more others are judged by the yardstick of our own culture, the more we neglect the context of other cultures, the more we refuse compliance with others.

- Knowledge of the host culture (KHC): This dimension indicates the degree of knowledge of an individual of the host culture specificities. According to Earley and Ang (2003) and Ward and Kennedy (1999), knowledge of standards, practices and specific agreements to the new culture is a determinant factor of adaptation to the host country. Understanding the new culture allows the individual to determine his view of himself and others and be able to identify with respect to its new situation. If the individual is in a situation that he does not control or situation that is not familiar to him, he will tend to be guided by the behavior of those around him. We recognize the better we master new culture (the IASB standards), the more we are able to compare it with our own culture (national accounting system), the more we are able to define our identification attitude (standardization strategy to adopt).

With these dimensions, we try to analyze the cultural dimension of social relations. As Perera et al. (2012) noted that there is a link between cultural values and accounting professionalism. Indeed, the phenomenon of acculturation highlights two antagonistic behaviors: a) resistance to change behavior that prevails conservatism of value systems, myths and symbolic codes to reproduce and maintain social order; b) collective dynamic representation of change that offers another vision of the world and a different conception of rationality and traditions received at the point of emergence of other cultures. 


\subsection{Cross-Cultural Validation of the measuring instrument}

We followed Vallerand's approach (1989) to ensure cross-cultural validation of our measuring instrument. This approach offers a series of systematic steps leading to the validation in French language of psychological questionnaire validated originally in English. It is divided into seven successive steps as follows:

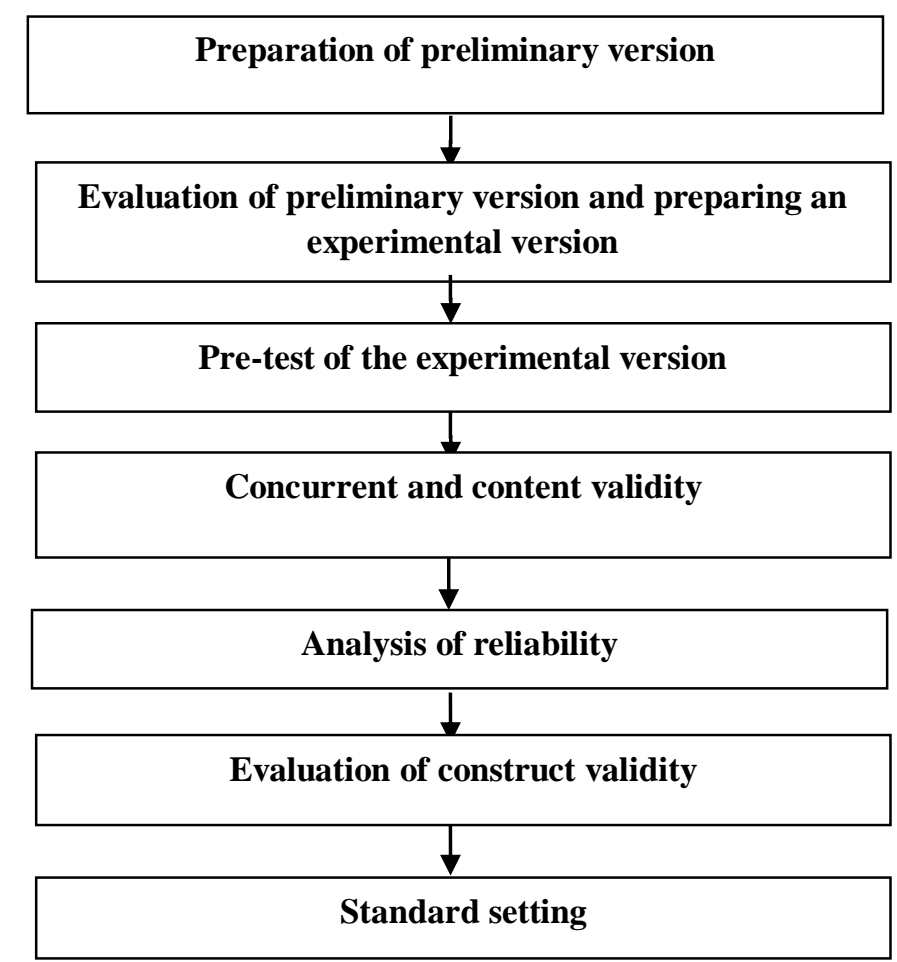

Figure 3. Sequential presentation of the various phases of systematic cross-cultural validation methodology of psychological tests

(Source: Vallerand, 1989)

As we intend to conduct a survey in different countries, we have prepared a version of the questionnaire in English and a preliminary version of the questionnaire in French using the technique of reverse translation (back-translation). The second step of the cross-cultural validation process is to compare the items from the second reverse translation (French $\rightarrow$ English) to the items of the original version in English. Comparing the two versions, we are assured of a fair return in the original language which is a sine qua non condition to our investigation. The pretest was conducted on a sample $(\mathrm{N}=25)$ of different nationalities (Tunisian, Algerian, French, Saudi), working in the accounting field (teachers, accountants, students) and randomly selected to judge the quality and the form of items. 
This qualitative test allowed us to make some changes relating to the order, length and the wording of some questions. As the exploratory survey being completed, we evaluated the concurrent and content validity of the French version. Pearson's test indicated high positive correlation at $1 \%$. Hence, there is a mismatch between the two versions. The recommended statistical instrument (Vallerand, 1989) and commonly used to estimate the degree of internal consistency of our instrument is Cronbach's alpha (Cronbach, 1951). The more inter-item covariance is strong, the greater the coefficient tends to 1 and the more the instrument is judged as having a high level of internal consistency. Cronbach's alpha of the original version is 0.791 which shows that all items share a common concept and contribute to the reliability of our measurement. Analysis of the internal consistency reliability of the translated version is 0.819 which is very close to the original version. This allows us to check how the reproduction of items from the original version to the French one was made as fair as possible.

After checking the reliability of our measuring instrument, we can begin our exploratory phase which allows us to test the robustness of our measurement scales through verification of internal consistency and factor structures.

The exploratory phase involves three steps and allows us to obtain usable questionnaires for the validation phase. The first step is to submit the two questionnaires to a small sample to detect potential problems that may encounter respondents. After checking the form and content of our questionnaires, we proceeded, in a second step, to collect data from different subjects in different countries by the non-probability sampling method. We chose two modes for administering the questionnaire: self-administration and via professional. We got seventy-two responses from fourteen countries. In a third step, we conducted a first analysis of data to determine the items that match the most with our built and to demonstrate the reliability of the selected items. The reliability of the measuring instrument test will be performed for each dimension by applying Cronbach's alpha for measuring the internal consistency of the scales and the sphericity of Bartlett's test, the index of adequacy Kaiser-Meyer-Olkin (KMO) and principal component analysis (PCA) to identify the factor structure of the scales and identify the most correlated items.

However, the last two steps of Vallerand's process (construct validity and standard setting) will be deferred to the section on the validation phase of our acculturation attitudes construct because they coincide with the objective of our research. Applying the same statistical techniques in this part, we will check the stability of results observed in exploratory phase and evaluate the construct validity of our measurement instrument. The results are detailed in the next section. 


\section{Results' presentation 4.1 Exploratory phase}

We can highlight the satisfactory level of total reliability indicators for the five dimensions. However, the elimination of some items has been delayed at the validation phase, which will allow us to verify our findings on a second larger sample.

The scale of IC: The statistical treatment of this scale showed an acceptable level of Cronbach's alpha of this scale (0.542), however, the deletion of items 10 and 17 would raise the value of this coefficient. The results of the PCA identify three main components of this scale with good overall variance (70.871).

The scale of the AWP: The coefficient of Cronbach's alpha of this scale is satisfactory. The application of PCA on this scale allows identifying a single principal component with an overall variance of $47.292 \%$. However, item 6 displays a relatively low score, yet its elimination is not conceivable for this phase.

The scale of OP: The reliability test of the indicators shows acceptable levels. Thus, we can see a Cronbach's alpha of about (0.672). PCA identifies two main components with acceptable total variance $(68.323 \%)$. The positioning of the item 12 separately asserts the low correlation of this item revealed by the test of the internal consistency while the results of the item 9 show the opposite (a satisfactory correlation with respect to the overall score and a non-belonging to a PCA factor). This finding is provisional pending the results in the validation phase.

The scale of EC: Analysis of the internal consistency reliability of this scale discloses a satisfactory level of the main indicators. The Cronbach is 0.775 and most items display satisfactory correlations with the total score of the scale. The five selected items constitute a single factor that explains $52.839 \%$ of the total variance. These results lead us to keep all items.

The scale of the KHC: The results point to a strong internal consistency of this scale measurement and display significantly higher scores. Factor analyzes clearly show the one-dimensional nature of this scale. All items, except item 23, load well on the only factor extracted and explain more than $60 \%$ of the variance.

\subsection{Validation phase}

In this final phase, we have obtained eight hundred seventy four (874) questionnaires whose respondents' profiles are presented in and the composition is represented in the table 2. 
Table 2. Sample distribution

\begin{tabular}{cc}
\hline Region & Number of collected questionnaires \\
\hline Africa & 395 \\
Europe & 263 \\
Asia & 131 \\
America & 75 \\
\hline Total & 864 \\
\hline
\end{tabular}

We have estimated the reliability of our dimensions to purify measurement scales before applying the validation tests (Appendix A).

The scale of IC: The statistical treatment of this scale showed a Cronbach's alpha of 0.407 . This coefficient is very low but we noted that the removal of items 8,10 and 17 would increase alpha to 0.582 which was also the case at the exploratory stage.

The PCA iterations demonstrate (Table 3) that these items will increase the total variance of $49.703 \%$ to $56.009 \%$. Thus, the final composition of the "Interpersonal Communication" dimension is defined by items 1,3 and 5 and represents well a onedimensional structure unlike the exploratory phase.

Table 3. KMO and Bartlett's Test and factor analysis of IC scale

\begin{tabular}{lcc}
\hline \multicolumn{2}{l}{ Kaiser-Meyer-Olkin Measure of Sampling Adequacy. } & $\mathbf{0 . 5 9 8}$ \\
\hline Bartlett's Test of Sphericity & df & 301.828 \\
Approx. Chi-Square & Sig. & 3 \\
& Items & 0.000 \\
& Factor \\
1. Building and maintaining relationships. & 0.822 \\
3. Interacting at social events. & 0.656 \\
5. Interacting with members of the opposite sex. & 0.758 \\
\multicolumn{2}{c}{ Variance explained } \\
\hline
\end{tabular}

The scale of the AWP: Cronbach's alpha is quite satisfactory (0.686) and most items display a satisfactory level of correlation with the overall score.

The results of the CPA (Table 4) coincide perfectly with those of the exploratory phase. By eliminating the item 6 , we observe a clear improvement of the total variance which rose from $49.671 \%$ to $61.495 \%$.

Table 4. KMO and Bartlett's Test and factor analysis of AWP scale

\begin{tabular}{|c|c|}
\hline Kaiser-Meyer-Olkin Measure of Sampling Adequacy. & 0.641 \\
\hline Bartlett's Test of Sphericity & 443.032 \\
\hline Approx. Chi-Square & 3 \\
\hline Sig. & 0.000 \\
\hline Items & Factor \\
\hline 2. Managing my academic/work responsibilities. & 0.838 \\
\hline 4. Working effectively with other work colleagues. & 0.764 \\
\hline $\begin{array}{l}\text { 7. Expressing my ideas to other work colleagues in a culturally appropriate } \\
\text { manner. }\end{array}$ & 0.747 \\
\hline Variance explained & $61.495 \%$ \\
\hline
\end{tabular}


The scale of OP: Applying the test of internal consistency, we found that the results revealed by the exploratory phase are confirmed. Indeed, we should remove the item 12. However, this deletion brings up a slight improvement in alpha coefficient if it is accompanied by elimination of item 9 also. This coefficient increases from 0.661 to 0.718 .

The PCA results support such decision since they allow raising the total variance. Like the exploratory phase, removing the item 12 has been confirmed by the results of the validation phase. However, after the use of iterations, elimination of item 9 allowed us to improve our results and to increase both the level of internal consistency and the overall variance (Table 5).

Table 5. KMO and Bartlett's Test and factor analysis of OM scale

\begin{tabular}{|c|c|}
\hline Kaiser-Meyer-Olkin Measure of Sampling Adequacy. & 0.653 \\
\hline Bartlett's Test of Sphericity & 532.880 \\
\hline Approx. Chi-Square & 3 \\
\hline СP & 0.000 \\
\hline Items & Factor \\
\hline $\begin{array}{l}\text { 13. I see that it is important to maintain relationships with individuals from } \\
\text { another culture. }\end{array}$ & 0.733 \\
\hline 15. I am able to easily tackle tough issues with others. & 0.817 \\
\hline 16. I manage to establish contact with people from other cultures. & 0.844 \\
\hline Variance explained & $63.965 \%$ \\
\hline
\end{tabular}

The scale of EC: Regarding the level of internal consistency of this dimension, we obtained quite satisfactory results and most items display a satisfactory level of correlation with the overall score.

The results of the factor analysis (Table 6) revealed a single main component containing all the items with a total variance of $42.468 \%$.

Table 6. KMO and Bartlett's Test and factor analysis of EC scale

\begin{tabular}{|c|c|}
\hline Kaiser-Meyer-Olkin Measure of Sampling Adequacy. & 0.695 \\
\hline Bartlett's Test of Sphericity & 578.004 \\
\hline Approx. Chi-Square & 10 \\
\hline 11 & 0.000 \\
\hline Items & Factor \\
\hline 11. I am aware of my qualities and my faults. & 0.533 \\
\hline 14. I can benefit from other's experience. & 0.608 \\
\hline 18. I am aware of cultural differences between countries. & 0.657 \\
\hline $\begin{array}{l}\text { 19. I adjust my cultural knowledge as I interact with people from a culture } \\
\text { that is unfamiliar to me. }\end{array}$ & 0.760 \\
\hline $\begin{array}{l}\text { 20. I check the accuracy of my cultural knowledge as I interact with people } \\
\text { from different cultures. }\end{array}$ & 0.678 \\
\hline Variance explained & $42.468 \%$ \\
\hline
\end{tabular}


The scale of $\mathbf{K H C}$ : Like the exploratory phase, the results keep a high internal consistency (0.859). However, alpha without the item 23 is significantly improved from 0.93 .

The PCA revealed a one-dimensional structure of this scale and a significant improvement in the total variance which rose from $67.813 \%$ to $82.825 \%$ after removing item 23 (Table 7).

Table 7. KMO and Bartlett's Test and factor analysis of KHC scale

\begin{tabular}{|c|c|}
\hline Kaiser-Meyer-Olkin Measure of Sampling Adequacy. & 0.847 \\
\hline Bartlett's Test of Sphericity & 2844.999 \\
\hline Approx. Chi-Square & 6 \\
\hline Sig. & 0.000 \\
\hline Items & Factor \\
\hline $\begin{array}{l}\text { 21. I know the objectives of the IASB (International Accounting Standards } \\
\text { Board). }\end{array}$ & 0.897 \\
\hline $\begin{array}{l}\text { 22. I know the legal and economic systems appropriate to the application of } \\
\text { IFRS. }\end{array}$ & 0.907 \\
\hline 24. I know the qualitative characteristics IFRS. & 0.907 \\
\hline 25. I know the content of IFRS. & 0.929 \\
\hline Variance explained & $82.825 \%$ \\
\hline
\end{tabular}

All indicators argue for a satisfactory reliability of different scales and the PCA has confirmed our theoretical predictions about the unidimensionality of our scales. The validity of the instrument indicates the degree to which an operationalization measures the concept that it is supposed to represent. The construct validity test verifies whether the studied phenomenon is well represented by the items of the scales of a questionnaire. Construct validity returns to verify that items measuring the same thing converge (convergent validity) and are distinguished from items measuring different phenomena (discriminant validity). We adopted Fornell and Larcker's procedure (1981) to calculate the convergent validity and discriminant validity of our construct. Table 8 shows that the dimensions obtained are reliable and valid.

Table 8. Convergent validity and discriminant validity

\begin{tabular}{ccc}
\hline Dimensions & $\begin{array}{c}\text { Convergent Validity } \\
\left(\boldsymbol{\rho}_{\mathbf{v c}}\right)\end{array}$ & $\begin{array}{c}\text { Discriminant Validity } \\
\left(\boldsymbol{\rho}_{\mathbf{v c}>\mathbf{c o r r}}\right)\end{array}$ \\
\hline & & $0.53>\delta^{2} \mathrm{CI}-\mathrm{PAT}=0.42$ \\
& 0.53 & $0.53>\delta^{2} \mathrm{CI}-\mathrm{EC}=0.05$ \\
Interpersonal & & $0.53>\delta^{2} \mathrm{CI}-\mathrm{OE}=0.26$ \\
Communication (IC) & & $0.53>\delta^{2} \mathrm{CI}-\mathrm{CC}=0.01$ \\
& 0.77 & $0.77>\delta^{2} \mathrm{PAT}-\mathrm{CI}=0.42$ \\
& & $0.77>\delta^{2} \mathrm{PAT}-\mathrm{EC}=0.23$ \\
Academic/Work & & $0.77>\delta^{2} \mathrm{PAT}-\mathrm{OE}=0.32$ \\
Performance (AWP) & & $0.77>\delta^{2} \mathrm{PAT}-\mathrm{CC}=0.00$ \\
& & $0.62>\delta_{\mathrm{EC}-\mathrm{CI}}=0.05$ \\
& 0.62 & $0.62>\delta^{2} \mathrm{EC}-\mathrm{PAT}=0.23$ \\
Ethnocentrism (EC) & & $0.62>\delta^{2} \mathrm{EC}-\mathrm{OE}=0.59$ \\
& & $0.62>\delta^{2} \mathrm{EC}-\mathrm{CC}=0.04$ \\
\hline
\end{tabular}




\begin{tabular}{ccc}
\hline Dimensions & $\begin{array}{c}\text { Convergent Validity } \\
\left(\boldsymbol{\rho}_{\mathrm{vc}}\right)\end{array}$ & $\begin{array}{c}\text { Discriminant Validity } \\
\left(\boldsymbol{\rho}_{\mathrm{vc}}>\mathbf{c o r r}^{2}\right)\end{array}$ \\
\hline & & $0.82>\delta^{2} \mathrm{OE}-\mathrm{CI}=0.26$ \\
& 0.82 & $0.82>\delta^{2} \mathrm{OE}-\mathrm{PAT}=0.32$ \\
Open-mindedness (OM) & & $0.82>\delta^{2} \mathrm{OE}-\mathrm{EC}=0.59$ \\
& & $0.82>\delta^{2} \mathrm{OE}-\mathrm{CC}=0.04$ \\
Knowledge of the host & $0.75>\delta^{2} \mathrm{CC}-\mathrm{CI}=0.01$ \\
culture (KHC) & 0.75 & $0.75>\delta^{2} \mathrm{CC}-\mathrm{PAT}=0.00$ \\
& & $0.75>\delta^{2} \mathrm{CC}-\mathrm{EC}=0.04$ \\
& $0.75>\delta^{2} \mathrm{CC}-\mathrm{OE}=0.04$ \\
\hline
\end{tabular}

The confirmatory factor analysis proved that the structure of the scales of measures proposed best reproduced reality. Statistical tests at this level have confirmed the good representation of different items retained for the studied phenomenon.

\section{Discussion of results}

At the end of construct's validation, we proceeded to the formation of indices for different dimensions. Table 9 shows the indices for the different countries in our sample. These achievements give us an idea about the matches that we can establish between the mental program of a population and the acculturation strategies which will be gradually adopted by individuals.

Table 9. Acculturation Indices

\begin{tabular}{cccccc}
\hline \multirow{2}{*}{ Countries } & \multicolumn{5}{c}{ Dimensions } \\
\cline { 2 - 6 } & IC & AWP & OM & EC & KHC \\
\hline South Africa & 12.333 & 13.556 & 13.333 & 20.778 & 18.333 \\
Albania & 23.500 & 15.000 & 11.500 & 15.000 & 18.000 \\
Algeria & 11.000 & 12.375 & 12.000 & 21.188 & 15.406 \\
Germany & 11.057 & 11.771 & 11.514 & 20.514 & 14.457 \\
Saudi Arabia & 12.511 & 14.064 & 12.745 & 21.447 & 7.021 \\
Bahrain & 10.368 & 12.947 & 11.474 & 20.947 & 12.211 \\
Belgium & 13.500 & 11.750 & 11.500 & 16.500 & 17.250 \\
Benin & 10.000 & 11.429 & 10.857 & 20.286 & 11.714 \\
Canada & 11.333 & 12.367 & 12.800 & 21.200 & 15.933 \\
Comores & 9.000 & 11.667 & 10.000 & 21.000 & 16.000 \\
Ivory Cost & 11.000 & 12.500 & 11.500 & 22.250 & 14.250 \\
Egypt & 11.893 & 12.750 & 11.893 & 20.143 & 14.393 \\
United Arab & & & & & \\
Emirate & 11.769 & 13.231 & 11.923 & 20.538 & 15.077 \\
Spain & 11.150 & 12.500 & 12.050 & 20.100 & 12.850 \\
United States & 12.089 & 12.089 & 11.911 & 21.356 & 12.022 \\
France & 10.840 & 11.679 & 11.123 & 20.358 & 14.198 \\
Greece & 12.000 & 11.000 & 12.000 & 20.000 & 16.000 \\
\hline
\end{tabular}

Vol. 18, No. 3 


\begin{tabular}{cccccc}
\hline \multirow{2}{*}{ Countries } & \multicolumn{5}{c}{ Dimensions } \\
\cline { 2 - 6 } & IC & AWP & OM & EC & KHC \\
\hline Italy & 14.667 & 13.667 & 7.667 & 14.667 & 7.667 \\
Jordan & 11.500 & 12.500 & 12.500 & 21.000 & 11.500 \\
Luxembourg & 15.000 & 14.000 & 12.000 & 22.000 & 15.000 \\
Morocco & 11.333 & 12.051 & 11.513 & 20.615 & 13.231 \\
Mauritania & 12.167 & 12.333 & 11.500 & 20.333 & 10.917 \\
Oman & 11.214 & 10.286 & 12.714 & 20.643 & 12.071 \\
Palestine & 10.000 & 12.000 & 12.000 & 22.000 & 11.200 \\
Netherlands & 12.348 & 11.652 & 11.522 & 19.696 & 7.652 \\
& & & & & \\
Qatar & 13.800 & 12.900 & 13.900 & 21.650 & 12.200 \\
United & & & & & \\
Kingdom & 11.682 & 11.773 & 11.455 & 20.000 & 10.545 \\
Serbia & 12.000 & 15.000 & 15.000 & 23.000 & 6.000 \\
Switzerland & 11.667 & 10.333 & 11.667 & 21.333 & 10.667 \\
Tunisia & 11.014 & 12.114 & 11.575 & 20.192 & 13.566 \\
\hline
\end{tabular}

According to Askary et al. (2008), culture has a powerful influence being the foundation of human behavior and social values and its impact on the accounting systems cannot be underestimated. Since the accounting profession is a vector of development of any accounting system in the world, many researchers have explicitly recognized its involvement in the standardization process, particularly on the implementation of IFRS (Salter \& Niswander, 1995; Hassabelnaby et al., 2003; Ashraf \& Ghani, 2005; Lopes \& Rodrigues, 2007). Professional organizations showed some resistance to adopt IFRS in order to retain their autonomy and power of accounting regulations. These organizations play a decisive role in the development of accounting systems as they establish relations with the body of accounting both nationally and internationally.

By taking Berry's typology, we conducted a cluster analysis to dynamic clouds using SPSS, which allows us to identify the different acculturation strategies used by respondents. The classification (Table 10) shows that there is a great disparity between Berry's four strategies.

Table 10. Number of cases in each of acculturation strategy

\begin{tabular}{ccc}
\hline Strategies & Number of observations & Percentage \\
\hline Marginalisation & 12 & $1.3 \%$ \\
Separation & 86 & $9.96 \%$ \\
Assimilation & 156 & $18.05 \%$ \\
Integration & 610 & $70.6 \%$ \\
Total & 864 & $100 \%$ \\
\hline
\end{tabular}

First, the integration strategy is widely adopted by people of different countries; it includes more than $70 \%$ of the observations. Second, we find the assimilation 
strategy with a fairly small percentage. Third, we found the strategy of separation and finally the marginalization strategy with a very low percentage. Berry (1997) suggested that studies of acculturation strategies found significant relationships with positive adaptation: integration is usually the strategy that has the most success, marginalization strategy is the least and assimilation and separation are intermediate strategies.

The interpretation proposed by Berry (1997) of this model shows that the integration strategy integrates a number of protective factors such as a desire of mutual accommodation, presence of positive mutual attitudes, absence of prejudices and discrimination, participation in two cultural communities having two social support systems and flexibility of personality. Conversely, marginalization implies the rejection of the dominant society combined with the refusal of our own culture, which means the presence of hostility and lack of social support. Assimilation involves suppression of our own culture so that separation implies the rejection of the dominant culture.

By adopting a strategy of integration, the individual try to maintain membership in a group and seek to join new groups if they can reinforce the positive aspects of its social identity. The social motivations of such an attitude lies in the need to be with others, the need of the other, the need for visibility and the need for social recognition. This integration strategy is characterized by great collective relationships, the importance of a democratic type of collective life that accepts productive debate between majority and minority and a clear rejection of all imposed authority where everyone has the power to admit its function, its practices and its social role. It promotes solidarity, negotiation, acceptance of differences and experience of the group.

It also results in values of autonomy, independence, self-control and control of others. As for the assimilation strategy, it is to abandon the culture of origin and to join a new dominant culture. This migration from one culture to another has been explained in two opposing ways depending on reports and expectations of individuals to the dominant culture. In an ameliorative perspective, the search of similarity by an individual comes from a desire to join a reference group; this requires a degree of uniformity required by this group. The greater the cohesion of a group increases, the greater the pressure toward uniformity becomes significant. In a pejorative vision, the need to build a reference and to look for a more social proof prevail the most for individuals in order to determine the legitimacy of their behavior. The collective is valued here as a refuge and protection against differences and cleavages. In this perspective, the individual is subjected to two processes of influence. An informational influence characterized by ambiguous, difficult or complex situations that do not directly treat the reality, whereas individuals need information to reduce uncertainty. This uncertainty creates a social dependency and the individual becomes dependent on others to get new information to validate its position. 
A normative influence stems from the fact that compliance is felt by the group as necessary to achieve its objectives. In this case, the individual will tend to bend to reference group norms and to submit to its pressure. The strategy of separation is characterized by a very low participation to collective relations and thus by a social anchorage of individuals in their reference groups where ideas and judgments allow them to shift towards the social world. Individuals are confined in a sort of cautious separatism and mobilize an arsenal of social resistance. The bridging cultures are felt as problematic and complex. This strategy reflects the desire of individuals to not deviate from the standards nested in their own culture and preserve their identity. Individuals consider their own society as a model and see any difference from this model as a sign of deviance from conformism. The latest strategy adopted by a very limited number of individuals is the marginalization strategy. This is a situation where the individual feels uncomfortable both in his own culture and the dominant culture. The individual is excluded or chooses to deviate from the norm of its society with a breakdown of social ties. Marginalization may result from self-will of the individual to live on the margins of society or be a consequence of segregation or social exclusion.

From these, we can have an idea about the tendency of actors operating in the accounting field to promote or oppose a migration to international standards. Accordingly, the attitudes of accountants may be expected to be derived from societal values with special reference to work-related values. As we explained above, acculturation attributes that we selected treat cognitive representations of individuals in interactions with other culturally diverse groups. These representations have shown that individuals (mainly accountants) of different cultures foster interpersonal exchanges and membership in heterogeneous groups, rely on professional sociability carriers of innovation and emphasize cultural learning. This may explain the strong recourse of different countries to IASB standards. According to the website of the IASB, $80 \%$ of the world use IFRS. Referring to prior studies, 61 of 101 countries applied the IFRS under a convergence strategy. This finding reveals that most countries chose the application of these standards while maintaining their national accounting system. This corresponds to the integration strategy that is most requested by individuals during cultural transitions. It then should be possible to establish the relationship between cultural value dimensions to accounting values which will, in turn, impact on accounting systems.

These results uncover a major social scene of a cultural transformation in the world. Indeed, new social complexities attached to economic, political and technological evolution created a sort of transitional space which can operate movements, exchanges, identifications process, argumentations and self-projections on other that help to risk transformations in cognitive representations of individuals. 


\section{Conclusion}

An extension of Berry's acculturation model is proposed here whereby societal values are expressed at the level of the accounting subculture. We suggest aggregates to measure and predict the effects of collective interaction internationally. The importance of culture in influencing the process of accounting policy formulation across nations focused on actors engaged in different cultures is explored rather than simply seeking deterministic patterns of pure relations of cause and effect, ignoring the complexity and richness of the social fact. The research in acculturation and adaptation provide consistent and potentially applicable conclusions. However, acculturation is one of the most complex and difficult of issues in social psychology because the process involves more than one culture (Berry, 1997). In an exploratory perspective based on the interpretive approach, we relied on research in social psychology and on Vallerand's approach to develop a measurement scale to determine the attributes of acculturation. The outcomes allowed us to identify five cultural dimensions: interpersonal communication, academic/work performance, open mindedness, ethnocentrism and knowledge of the host culture. We also found that the integration strategy is the most requested by individuals when they are in a new cultural context. This finding explains the high use of the convergence strategy by countries, which would enable them to implement IFRS while maintaining their own accounting system.

Our research settles the confines of ethnic approach which has the potential to draw much larger and culturally radical conclusions that are beyond the scope of a single culture (Macnab et al. 2010). However, the choice of this approach inevitably exposes us to many critics. The existence of subcultures within the same country to be taken into account in the generalization of the findings, it should not be assumed that national identity is the same as the cultural identity as crops in countries are often heterogeneous. Also, in a multi-ethnic country, the national culture can be complex due to the existence of a strong ethnic culture microenvironment (Sarwono \& Armstrong, 2001). Therefore, research into a culturally diverse environment should go beyond the national culture and reach regional context.

Compared with previous studies, our research has taken an exploratory appearance based on purely psychosocial studies through which we determined new cultural dimensions to thirty countries. A study on the determinants of acculturation attitudes is added to previous literature. This would allow to lay the foundations for further extension to our work. Indeed, culture is a conducive area to achieving innovative academic research thereby the development of new measures and dimensions that we identified could be applied in other fields of investigation including research in culture and accounting. Similarly, an additional study of our measuring scale could be conducted on a larger sample of countries and could therefore fructify our database. 


\section{References}

Ang, S., Van Dyne, L. \& Koh, C. (2006) "Personality correlates of the four-factor model of cultural intelligence", Group \& Organization Management, vol. 31, no. 1: 100-123

Ang, S., Van Dyne, L., Koh, C., Yee Ng, K., TemplerK.J., Tay, C. \& Chandrasekar, N.A. (2007) "cultural intelligence: its measurement and effects on cultural judgment and decision making, cultural adaptation and task performance", Management and Organization Review, vol. 3, no. 3: 335-371

Archambault, J.J. \& Archambault, M.E. (2003) "A multinational test of determinations of corporate disclosure", The International Journal of Accounting, vol. 38, no. 2: 173-194

Arora, P. \& Rohmetra, N. (2010) "Cultural intelligence: leveraging differences to bridge the gap in the international hospitality industry", International Review of Business Research Papers, 6: 216-234

Ashraf, J. \& Ghani, W.I. (2005) "Accounting development in Pakistan", The International Journal of Accounting, vol. 40, no. 2: 175-201

Askary, S., Yazdifar, H. \& Askarany, D. (2008) "Culture and accounting practices in Turkey", International journal of Accounting, Auditing and Performance Evaluation, vol. 5, no. 1: 66-88.

Belkaoui, A. (1990) "Cultural determinism and the perception of accounting concepts", The Middle East Business and Economic Review, pp. 33-37

Berry, J. W. (1997) "Immigration, acculturation and adaptation", Applied Psychology: An International Review, vol. 46: 5-68

Berry, J. W. (2004) "Fundamental psychological processes in intercultural relations", In D. Landis, J. Bennett, \& M. Bennett (Eds.), Handbook of intercultural training (pp. 166-184). Thousand Oaks: Sage.

Bollinger, D. \& Hofstede, G. (1987) Les différences culturelles dans le management : comment chaque pays gère-t-il ses hommes?, Paris: Éditions d'Organisation

Dahawy, K., Merino, B.D. \& Conover, T.L. (2002) "The conflict between IAS disclosure requirements and the secretive culture in Egypt", Advances in International Accounting, vol. 15: 203-228

Ding, Y., Jeanjean, T. \& Stolowy, H. (2005) "Why do national GAAP differ from IAS? The role of culture", The International Journal of Accounting, vol. 40: 325-350

Doupnik, T., \& Salter, S. (1995) "External environment, culture, and accounting practice: A preliminary test of a general model of international accounting development", International Journal of Accounting, vol. 30, no. 3: 189-202

Dumontier, P. \& Teller, R. (2001) Faire de la recherche en comptabilité financière, Paris: Vuibert

D'Arcy, A. (2001) "Accounting classification and the international harmonisation debate: an empirical investigation", Accounting, Organizations and Society, vol. 26, no. 4-5: 327-349 
Earley, P. C. \& Ang, S. (2003) Cultural intelligence: Individual interactions across cultures, CA: Stanford University Press, Stanford

Fornell, C. \& Larcker, D.F. (1981) "Evaluating structural equation models with unobservable variables and measurement error", Journal of Marketing Research, vol. 18, no. 1: 39-50

Gelfand, M. J., Nishii, L. H., Holcombe, K. M., Dyer, N., Ohbuchi, K. \& Fukuno, M. (2001) "Cultural influences on cognitive representations of conflict: Interpretations of conflict episodes in the United States and Japan”, Journal of Applied Psychology, vol. 86, no. 6: 1059-1074

Gray, S.J. (1988) "Towards a theory of cultural influence on the development of accounting systems internationally", Abacus, vol. 24, no. 1: 1-15

HassabElnaby, H.R., Epps, R.W. \& Said, A.A. (2003) "The impact of environmental factors on accounting development: An Egyptian longitudinal study", Critical Perspectives on Accounting, vol. 14: 273-292

Hofstede, G. (1980) Culture's Consequences: International Differences in WorkRelated Values, CA: Sage Publications, Beverly Hills

Hofstede, G.H. (1987) "Relativité culturelle des pratiques et théories de l'organisation", Revue Française de Gestion, vol. 64: 10-20

Jaggi, B. \& Low, P.Y. (2000) "Impact of culture, market forces, and legal system on financial disclosures", The International Journal of Accounting, vol. 35: 495-51

Joshi, P.L. \& Ramadhan, S. (2002) "The adoption of international accounting standards by small and closely held companies: evidence from Bahrain", The International Journal of Accounting, vol. 37: 429-440

Judge, W.Q., Li,S. \& Pinsker, R. (2010) "National Adoption of International Accounting Standards: An Institutional Perspective", Corporate Governance: An International Review, vol. 18, no. 3: 161-174

Köhler, W. (1951) "Relational determination in perception", In L.A. Jeffress (Eds.), Cerebral mechanisms in behavior, the Hixon symposium (pp. 200-243). New York: Wiley

Lazarsfeld, P.F. (1958) "Evidence and inference in social research", Deadalus, vol. 87: $99-130$

Lévi-Strauss, C. (1952) Race et Histoire, Paris: UNESCO.

Lievens, F., Harris, M. M., Van Keer, E. \& Bisqueret, C. (2003) "Predicting crosscultural training performance: The validity of personality, cognitive ability, and dimensions measured by an assessment center and a behavior description interview", Journal of Applied Psychology, vol. 88, no. 3: 476-489

Lopes, P.T. \& Rodrigues, L.L. (2007) "Accounting for financial instruments: An analysis of the determinants of disclosure in the Portuguese stock exchange", The International Journal of Accounting, vol. 42, no. 1: 25-56

MacNab, B., Worthley, R. \& Jenner, S. (2010) "Regional cultural differences and ethical perspectives within the United States: Avoiding pseudo-emic ethics research", Business and Society Review, vol. 115, no. 1: 27-55 
Masgoret, A.M., \& Ward, C. (2006) "Cultural learning approaches to acculturation". In D.L. Sam \& J.W. Berry (Eds.), Cambridge handbook of acculturation psychology (58-77), UK: Cambridge University Press

McGee, W. J. (1898) "Piratical acculturation", American Anthropologist, vol. 11: 243-249

Nurunnabi, M. (2015) "Tensions between politico-institutional factors and accounting regulation in a developing economy: Insights from institutional theory", Business Ethics: A European Review, vol. 24, n. 4: 398-424

Perera, M. H. B. (1989) "Accounting in developing countries: a case for localized uniformity", British Accounting Review, vol. 21: 141-158

Perera, H., Cummings, L. \& Chua, F. (2012) "Cultural relativity of accounting professionalism: Evidence from New Zealand and Samoa", Advances in Accounting, vol. 28, no. 1: 138-146

Sainsaulieu, R. (1997) Sociologie de l'Entreprise: Organisation, Culture et Développement, Paris: Presses Sciences Po et Dalloz

Salter, S.B. \& Niswander, F. (1995) "Cultural influence on the development of accounting systems internationally: A test of Gray's (1988) theory”, Journal of International Business Studies, vol. 26, no. 2: 379-397

Samuel, S. \& Manassian, A. (2011) "The rise and coming fall of international accounting research", Critical Perspectives on Accounting, vol. 22: 608-627

Sarwono, S. \& Armstrong, R. (2001) "Micro-cultural differences and perceived ethical problems: an international business perspective", Journal of Business Ethics, vol. 30, no. 1: 41-56

Searle, W. \& Ward, C. (1990) "The prediction of psychological and sociocultural adjustment during cross-cultural transitions", International Journal of Intercultural Relations, vol. 14, no. 4: 449-464

Shima, K.M. \& Yang, D.C. (2012) "Factors affecting the adoption of IFRS", International Journal of Business, vol. 17, no. 3: 276-298

Takeuchi, R., Yun, S. \& Tesluk, P. E. (2002) "An examination of crossover and spillover effects of spouse and expatriate adjustment on expatriate outcomes", Journal of Applied Psychology, vol. 8: 655-666

Usunier, J.C. (1992) Commerce entre cultures: Une approche culturelle du marketing international, Paris : PUF

Vallerand, R.J. (1989) "Vers une méthodologie de validation transculturelle de questionnaires psychologiques : implications pour la recherche en langue française“, Psychologie Canadienne, vol. 30: 662-689

Violet, W.J. (1983) "The Development of International Accounting Standards: An anthropological perspective", The International Journal of Accounting, vol. 18: $1-12$

Ward, C. \& Kennedy, A. (1999) "The measurement of sociocultural adaptation", International Journal of Intercultural Relations, vol. 23, no. 4: 659-677

Ward, C. \& Rana-Deuba, A. (1999) "Acculturation and adaptation revisited", Journal of Cross-Cultural Psychology, vol. 30, no.4: 372-392 
Ward, C. \& Searle, W. (1991) "The impact of value discrepancies and cultural identity on psychological and sociocultural adjustment of sojourners", International Journal of Intercultural Relations, vol. 15: 209-225

Zeghal, D. \& Mhedhbi, M. (2006) "An analysis of the factors affecting the adoption of international accounting standards by developing countries", The International Journal of Accounting, vol. 41: 373-386

Zinetti-Bertschy, A., Frendenrich-Mühlebach, A., Rosner, M., Guimon, J. \& Maercker, A. (2004) "First steps towards the validation of the relations to others French scale (ERA: Echelle de Relations avec les Autres)", European Journal Psychiatrique, Supplement: 85-92 
Appendix A. Reliability statistics of different scales

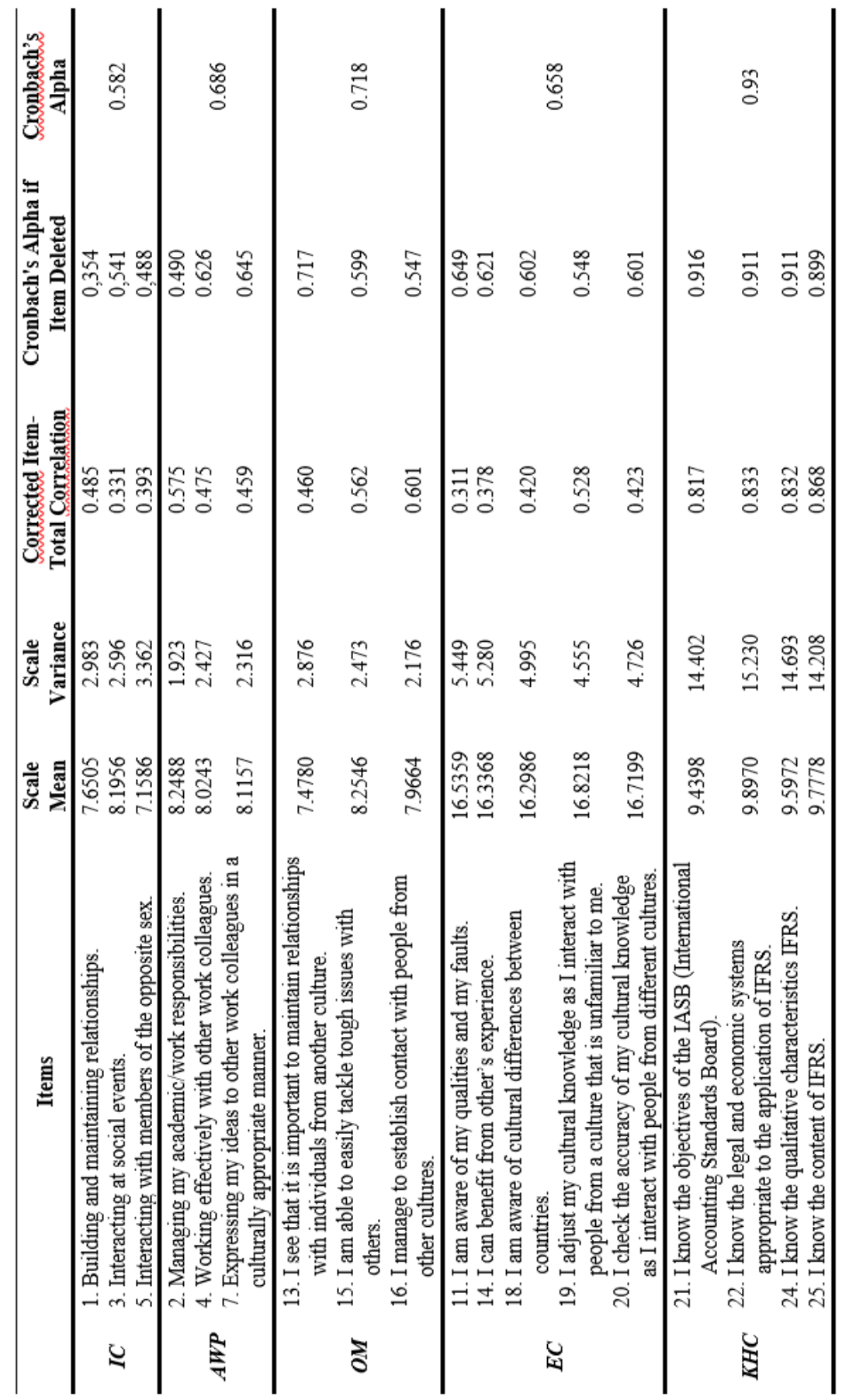

